\title{
Early diagenesis in sediments of a Mediterranean lagoon and its relationship to hypoxia
}

\author{
DANIELE BRIGOLIN ${ }^{1}$, CHRISTOPHE RABOUILLE ${ }^{2}$, \\ CLÉMENT DEMASY ${ }^{3}$, BRUNO BOMBLED ${ }^{4}$, GAEL \\ MONVOISIN $^{5}$ AND ROBERTO PASTRES $^{6}$ \\ ${ }^{1}$ Università IUAV di Venezia \\ ${ }^{2}$ LSCE CEA-CNRS-UVSQ \\ ${ }^{3}$ Laboratoire des Sciences du Climat et de l'Environnement, \\ UMR CEA-CNRS-UVSQ et IPSL, Université Paris-Saclay \\ ${ }^{4}$ LSCE -CNRS \\ ${ }^{5}$ Université Paris-Saclay, CNRS, GEOPS \\ ${ }^{6}$ Università $\mathrm{Ca}^{\prime}$ Foscari Venezia \\ Presenting Author: dbrigolin@iuav.it
}

The interaction between sediment biogeochemistry and hypoxia has been largely investigated in ecosystems periodically subjected to the presence of large anoxic zones, and in landlocked stratified environments. Less attention has been provided to shallow water systems in which stratification is absent, and the wind is expected to have a major role in water mixing and reoxygenation. The present work focuses on sediments of the Venice lagoon, located in a densely populated area subjected to multiple stressors, with the goal of increasing the understanding of the links between diagenetic processes occurring in sediments and the dynamics of dissolved oxygen. Sediment data were collected over three consecutive years (2015-2017) during the spring-summer season, at 5 different stations located in different areas of the lagoon. Measured variables included sediment porosity, grain size and solids composition, porewater microprofiles of $\mathrm{O}_{2}, \mathrm{pH}$ and $\mathrm{H}_{2} \mathrm{~S}$, porewater profiles, including DIC, Alk, $\mathrm{NH}_{4}^{+}, \mathrm{NO}_{3}^{-}$, dissolved $\mathrm{Fe}$. In addition, time series of long-term water quality monitoring data (2005-2017) collected by the Venice Water Authority were analyzed, to assess the tendency of the sampled areas to undergo hypoxia. The latter analysis, which was performed at 4 monitoring stations, pointed out that the lagoon waters experience low oxygen concentrations in summer months, with median values below $50 \%$ saturation, and that consecutive days with minimum saturation values below $25 \%(55 \mathrm{mmol} / \mathrm{l})$ can occur, and last one week or more. The inter-annual consistency of data collected by sediment coring was first performed and, subsequently, sampled stations were divided in two groups based on their diagenetic intensity. At intense and moderate diagenesis stations the average DIC flux, estimated trough a simple steadystate model were respectively of 2.8 and $1.0 \mathrm{mmol} \mathrm{m}^{-2} \mathrm{~d}^{-1}, \mathrm{SO}_{4}{ }^{2-}$ fluxes of 1.6 and $0.4 \mathrm{mmol} \mathrm{m} \mathrm{m}^{-1}$, while diffusive oxygen uptake fluxes, calculated from the sediment microprofiles data, were of 28.5 and $17.5 \mathrm{mmol} \mathrm{m}^{-2} \mathrm{~d}^{-1}$. At the organic-rich stations, dissolved sulfide accumulated in porewaters very near the sediment-water interface, reaching values of $0.7 \mathrm{mM}$ at $10 \mathrm{~cm}$. An aspect of relevance concerns the consequences that hypoxia can have on water bodies through release of sulfide. 